\title{
Arquitectura doméstica Y PROTECCIÓN DEVOTA: \\ IMÁGEENES RELLIOIOSAS EN LAS FACHADAS DE LOS CHALETS MARPLATENSES
}

Domestic architecture and devout protection:

religious images on the facades of the Mar del Plata chalets

Lorena Marina Sánchez*, Analía Ester Benitez **

\author{
Fecha de recibido: \\ 31 Julio 2020 \\ Fecha de aceptado: \\ 6 Noviembre 2020
}

\begin{abstract}
RESUMEN. Las relaciones entre la arquitectura doméstica, que compone gran parte del paisaje urbano de cada ciudad, y las imágenes protectoras, que se imbrican en sus fachadas, expresan las transformaciones sociomateriales tangibles e intagibles a través del tiempo. Entre múltiples manifestaciones, en las fachadas se destacan los mensajes ligados a la religiosidad popular, en particular sus significados vinculados a la veneración y a la protección. En este sentido, en Argentina, el culto católico resulta mayoritario y ha generado diferentes improntas, como acontece en la ciudad de Mar del Plata mediante la expresividad forjada en los frentes de sus chalets homónimos. Por ello y desde una perspectiva principalmente cualitativa apoyada por datos cuantitativos, mediante la interpretación de fuentes primarias y secundarias, se propone analizar las imágenes religiosas subsistentes en este tipo de viviendas, dentro de las dos lomas inicialmente pobladas que atesoran una relevante densidad de chalets, para ampliar su comprensión y los valores asociados.
\end{abstract}

Palabras clave: ciudad, imagen religiosa, protección, vivienda, veneración.
ABSTRACT. The relationships between the domestic architecture that makes up much of the urban landscape of each city and the protective images that are embedded into their facades, express the tangible and intangible sociomaterial transformations through time. Among many manifestations, the facades highlight the messages linked to popular religiosity, in particular their meanings linked to veneration and protection. In this sense, in Argentina the Catholic cult is majority and it has generated different imprints, as it happens in the city of Mar del Plata through the expressiveness forged in the facades of the chalets "Mar del Plata style". Therefore, and from a mainly qualitative perspective supported by quantitative data, through the interpretation of primary and secondary sources, it is proposed to analyze the religious images that remain in this type of housing, within the two initially populated hills that treasure a relevant density of chalets, to expand their understanding and the associated values.

Key words: city, religious image, protection, living place, veneration. 


\section{Durante las décadas del 60 y 70 , LA CUESTIÓN DE LA VIVIENDA SOCIAL FUE CENTRO DE PREOCUPACIÓN EN LAS POLITICAS DE DESARROLLO DE MUCHOS DE LOS PAÍSES DEL CONO SUR AMERICANO.}

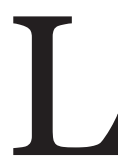
as relaciones entre la arquitectura doméstica, que compone gran parte del paisaje de cada ciudad, y las imágenes protectoras, que se imbrican en sus fachadas, expresan las transformaciones sociomateriales tangibles e intagibles a través del tiempo. La fachada constituye un espacio privilegiado que materializa el límite interior-exterior y que ha sido objeto de arduas discusiones teóricas sobre sus diversas jerarquías funcionales y ornamentales, entre caracterizaciones "clásicas" y "modernas" (Loos, 1972; Argan, 1977; Venturi et al., 1978, entre otros autores tradicionales de fines del siglo xx). En el transcurso de la historia, los frentes de las más diversas edificaciones han sido portadoras de información $\mathrm{y}$ han procurado transmitir mensajes a los observadores. Así, las fachadas han sido -y son- espacios discursivos relevantes, eventos comunicativos en sí mismos, que narran a través de su materialidad y su simbología, y que pueden ser leídas según la percepción de quienes las observan (Hojman y Rimbaud, 2018; Benítez, A., 2017, Gendelman y Aiello, 2010).

Los mensajes involucrados en las portadas se dividen en dos grupos: los que informan las funciones del edificio, es decir, comunican su uso; o los que exhiben información simbólica, connotaciones y asociaciones subjetivas. El desciframiento en este segundo caso implica ideas filosóficas, políticas, devotas, sociales y culturales, usualmente en relación. Así, en este marco, resultan destacados los mensajes asociados a la religiosidad popular, ${ }^{1}$ en particular sus significados vinculados a la veneración y la protección divina.

En la historia argentina, la religión cristiana católica se constituyó en culto preeminente de la nación, reflejándose en diversas manifestaciones. Así, el sentido religioso del pueblo cristiano - dice la Iglesia Católica - ha encontrado en todos los tiempos su expresión en torno a la vida sacramental de la Iglesia; por ejemplo, "las veneraciones de las reliquias, las visitas a santuarios, las peregrinaciones, las procesiones, los vía crucis, las danzas temáticas, los rezos del rosario, las medallas", entre otros (Catecismo de la Iglesia Católica, 1992, n.1674). En estas expresiones puede percibirse el modo en que la fe recibida se encarna en una cultura y se transmite (Francisco, P.P., 2013);

\footnotetext{
1 En el Directorio de la Piedad Popular y Liturgia (DPPL), la Congregación para el Culto Divino y la Disciplina de los Sacramentos diferencia "piedad popular" y "religiosidad popular": la "piedad popular" hace referencia a los actos culturales en el ámbito de la fe cristiana, mientras que la "religiosidad popular" aborda las manifestaciones universales de la dimensión religiosa del hombre (entre las cuales la piedad popular es una de ellas). En los documentos que no se centran en disquisiciones teológicas, ambas nociones se utilizan indistintamente, por lo que a los fines de este artículo se utilizarán como sinónimos.

La dimensión personal es el modo individual de relacionarse con Dios, con la Santísima Virgen y con los Santos; la dimensión comunitaria es particularmente participativa, en la cual intervienen sacerdotes, religiosos y laicos.
} 


\section{Aquí la adaptabilidad, QUE PODRÍA QUEDAR CIRCUNSCRIPTA AL ÁMBITO ACADÉMICO, PARTICIPA DE UNA REVISIÓN DE LA VIVIENDA, INCLUSODESDE LOS MODOS DE HABITAR.}

inculturación que se pronuncia también en la exhibición de imágenes en las fachadas de algunos tipos de viviendas.

Dentro de la piedad popular es característica la riqueza expresiva que emplea elementos simbólicos y estéticos para la transmisión de la fe, y la transmisión de los misterios de la vida de los personajes bíblicos principales y de los Santos más populares. Esto se traduce en gestos, textos y fórmulas, canto y música, lugares, tiempos litúrgicos e imágenes; todos elementos que se viven en dos dimensiones: la personal y la comunitaria. ${ }^{2}$ En la particularidad de las imágenes colocadas en los frentes de cada hogar, se presenta una "auténtica catequesis", que manifiesta la fe cristiana en forma pública (Pérez Ortega y García Serrano, 1969).

Así como en las casas, ámbitos privilegiados de las familias, "ambientes de vida y de trabajo; en algunas ocasiones, también las calles y las plazas se convierten en espacios de manifestación de la fe" (DPPL, 2002, n.19). Basta pensar en las fachadas-retablo del Barroco, que buscaban sacralizar el espacio público, mediante la transmisión de mensajes a la plaza, el mercado, la calle, el escenario cotidiano, donde transcurría la vida, para que fueran contemplados por todos. De modo análogo, si las fiestas religiosas sacralizan el tiempo y nos sumergen en el tiempo sagrado, y las fachadas-retablo sacralizan el espacio público, entonces también las portadas de las viviendas, con estas imágenes -en su sencillez doméstica-, co-construyen un mensaje, propio del espacio sagrado inscrito en el contexto urbano, por lo general, laico.

2 La dimensión personal es el modo individual de relacionarse con Dios, con la Santísima Virgen y con los Santos; la dimensión comunitaria es particularmente participativa, en la cual intervienen sacerdotes, religiosos y laicos.
En este marco, la ciudad de Mar del Plata, fundada en 1874 dentro de la provincia de Buenos Aires, resulta una aglomeración intermedia que ha forjado un tipo de residencia particularmente expresiva en sus fachadas: los chalets "estilo Mar del Plata". Esta ciudad distinguida por su amplio borde costero sobre el océano Atlántico, tempranamente fue receptora de inmigrantes y construyó, progresivamente, una dinámica caracterización balnearia y portuaria (Cacopardo, 2003). En estos procesos, en especial en el marco turístico estival inicialmente instituido, se erigieron grandes residencias ligadas al pintoresquismo europeo. Los paisajes marítimos, la topografía de la ciudad, la mirada posicionada en diferentes referentes balnearios europeos y el poder de los grupos sociales más aventajados de principios del siglo $\mathrm{xx}$, entre otros factores, presentaron un ámbito fértil para el impulso de esta corriente arquitectónica. El pintoresquismo presentó evoluciones que desde el siglo xviII posibilitaron su consideración como categoría estética e implicaron, en arquitectura, una particular relación sensible entre lo construido y la naturaleza. Hacia fines del siglo XIX, esta tendencia se caracterizó por el carácter extraurbano, la asimetría, el contraste de volúmenes y la exposición de materiales (Cova y Gómez, 1982; Ballent, 2004; París Benito y Novacovsky, 2009; Gómez Pintus, 2009).

Esta tendencia acompañó los procesos urbano-arquitectónicos de la ciudad, en especial en el desarrollo de las dos lomas originariamente habitadas; la loma norte (cuya principal denominación se conocerá como loma de Santa Cecilia en honor a la capilla allí localizada, referencia original del trazado de la ciudad de 1874) y la loma sur (con múltiples nombres hasta su designación como loma de Stella Maris, también en honor al templo que corona su cima, bendecido en 1912). Desde 1920, en la ciudad se forjó una transformación hacia una democratización balnearia, acompañada por un mayor afianzamiento de la población estable. Hacia 1930 se consolidó una ciudad más abierta al veraneo junto con una mayor expansión del turismo. La familia, por su parte, también comenzaba a atravesar cambios cuantitativos y cualitativos, alejándose de los parámetros de la familia extensa. La construcción de villas, de acuerdo con las nuevas formas de vacacionar y habitar la ciudad, resultó poco apropiada en sintonía con los cambios sucedidos. La ciudad requirió conjugar las grandes residencias con chalets de diferentes escalas destinados a nuevos grupos sociales medios, ideados por arquitectos e ingenieros -incluso algunos ya establecidos localmente- 
e innumerables constructores e idóneos. Hacia mediados de siglo, el turismo masivo fomentado por las políticas nacionales, junto con una población estable al servicio del balneario y la ciudad, promovieron la diseminación de un tejido con predominancia de pequeños chalets pintoresquistas.

Estas residencias adoptaron características únicas que originaron una vertiente local denominada "estilo Mar del Plata". Sus principales rasgos tradujeron las premisas pintoresquistas de las primigenias villas costeras junto con particularidades de las corrientes californianas norteamericanas, entre otras. Asimismo, las fachadas atesoraron la mayor relevancia, ya que allí se condensaron los principales tratamientos materiales, técnicos, tecnológicos y simbólicos (Cova y Gómez Crespo, 1982; Sánchez, L. M., 2008). En apogeo entre 1930 y 1950, adaptaron creativamente las volumetrías asimétricas y yuxtapuestas, destacándose los múltiples techos inclinados, las chimeneas reales o ficticias, un jardín al frente y el porche, mediante materialidades como la teja cerámica (en especial la colonial), el revoque blanqueado (rústico, especialmente texturado), la madera (con técnicas como el "hachado"), la piedra (local, denominada "Mar del Plata", tratada en aparejos como el "bastón roto" al revestir los muros en forma total o "salpicada") y particulares herrajes (preferentemente de hierro forjado). El carácter total extraurbano y la manifestación del orgullo propietario por haber logrado adquirir esta clase de vivienda, en paralelo, se completó con ornamentaciones como duendes de jardín, inscripciones con los nombres de los constructores o arquitectos intervinientes, letreros con los nombres de los propietarios -e incluso con animadas leyendas- y la colocación de vanos para exhibir imágenes principalmente religiosas.

En este marco, el presente artículo propone analizar las diversas presencias de imágenes pías en los frentes de estos chalets, desde una mirada sociomaterial, para ampliar la comprensión de estos bienes y sus valores. Esta perspectiva investigativa, sin antecedentes, espera así iluminar nuevas miradas y, por ende, nuevas indagaciones y tratamientos preservacionistas asociados.

\section{METODOLOGÍA}

El análisis propuesto se abordó desde una perspectiva principalmente cualitativa apoyada por datos cuantitativos, mediante la interpretación de fuentes primarias y secundarias.

Para ello se seleccionaron fragmentos de interés dentro de las dos lomas de la ciudad
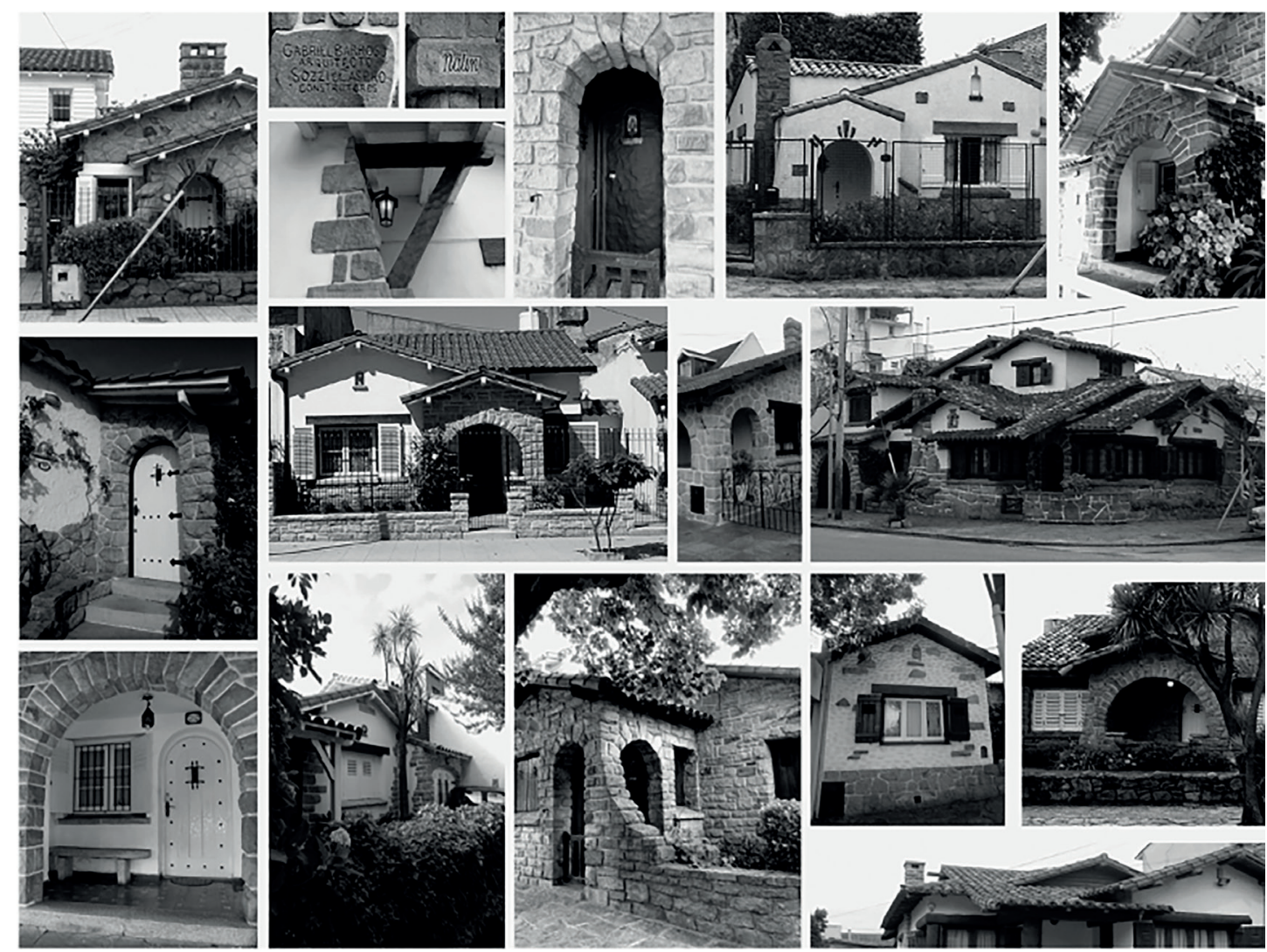

FIGURA 1. MOSAICO CON DETALLES DE CHALETS "ESTILO MAR DEL PLATA" ANALIZADOS EN LOS BARRIOS DE STELLA MARIS Y SANTA CECLLIA. FUENTE: FOTOGRAFIAS DE LAS AUTORAS. 
mencionadas, debido a la relevancia de los bienes "estilo Mar del Plata" supervivientes. Ambos sectores devenidos en barrios constituyeron -y constituyen- enclaves significativos en la conformación de la ciudad y su identificación balnearia, donde surgieron y proliferaron disímiles escalas de viviendas pintoresquistas que signaron el paisaje histórico-urbano local hasta la actualidad; villas (con envergaduras destacadas) y chalets (de menor escala).

En particular, en la sección norte de La Perla se registraron los chalets de menor escala y en Stella Maris se reconocieron versiones de diversas escalas. En La Perla se verificó in situ el relevamiento parcelario de sus 94 manzanas completas e irregulares, donde se identificaron cerca de 400 viviendas pintoresquistas, en su mayoría "estilo Mar del Plata”. En Stella Maris se realizó el relevamiento parcelario de sus 102 manzanas completas e irregulares, donde se constataron más de 920 residencias pintoresquistas, delos cuales más de 300 casos se inscribieron en el estilo analizado. Así, la densidad de los bienes en análisis, verificada en ambos sectores, evidenció la relevancia del legado doméstico, de valores principalmente contextualesambientales, que todavía caracteriza el paisaje contemporáneo. Dentro del análisis de estos bienes, paralelamente se focalizó en la presencia -o ausencia- de imágenes religiosas en los vanos de las fachadas.

En este relevamiento, asimismo, se condensaron indagaciones sobre los procesos históricos urbanos, arquitectónicos y sociales ligados al devenir de estas viviendas, mediante el cruce de fuentes escritas (investigaciones previas, artículos científicos, expedientes municipales de más de 100 casos) y gráficas (avisos publicitarios, planimetrías, fotografías e imágenes aéreas). La articulación de los resultados se procesó a través de matrices síntesis que posibilitaron una mirada integral, y a su vez particular, del foco analítico explorado.

\section{ANÁLISIS DE LAS IMÁGENES RELIGIOSAS EN LAS FACHADAS}

En el corpus de chalets analizados, más del $35 \%$ todavía posee hasta tres vanos por frente para la colocación de imágenes religiosas. Estas profundidades murarias presentan, asimismo, una gran diversidad de formas: rectángulos sencillos, rectángulos con arco y hornacinas son las más habituales, pero también pueden encontrarse de forma triángular. ${ }^{3}$ Exhibidas en los frentes y guarecidas por alguna reja o pequeñas cubiertas sobresalientes, generalmente de tejas cerámica, las hornacinas se destacan en las fachadas principales. En su mayoría dibujadas en los planos municipales originales, ${ }^{4}$ se concentran en los ingresos en estrecha relación con los porches, así como en los mojinetes -muros de remate triangular que separan las aguas de la cubierta- de manera más íntima o más expuesta.

Si bien se desconoce el origen de la fundamentación de estos vanos, ya sea como licencias de los constructores, pedidos de los propietarios, recursos recurrentes "de moda" o combinación de múltiples aspectos, es segura la inclinación religiosa compartida debido a las imágenes allí colocadas. La costumbre de ubicar este tipo de figuras en las portadas ha ido adaptándose a la estética de cada época, lugar y cultura, y siempre ha permanecido como una "ventana a la sacralidad", que ha permitido conexiones con otras dimensiones no terrenales, en este caso con la religión cristiana que connota un auxilio divino. Es interesante recordar que el pintoresquismo tuvo mayormente expresiones en las intersecciones de la arquitectura y la naturaleza, donde es factible reflejar la presencia de un Dios creador. En estos vanos se expresa, de alguna manera, esta recuperación de la religiosidad en forma pública. Asimismo y de marcada tradición española, enlazada a las descendencias inmigratorias locales, se reconoce una herencia en la preocupación por el amparo residencial del santo dela devoción ${ }^{5}$ del dueño de cada casa. Así, la inclusión de imágenes beatas ha oscilado entre la protección y la veneración, junto a sus múltiples amalgamas.

La veneración "por las imágenes sagradas pertenece, de hecho, a la naturaleza de la piedad católica" (DPPL, 2002, n.18), a cuya formación ha contribuido frecuentemente la devoción popular. Esta veneración se realiza en consciencia de que "los honores tributados

3 La figura de triángulo posee significados propios: lo indeformable, el 'ojo' de Dios en la tradición judaica, la Trinidad en la tradición cristiana e incluso diversos significados masónicos. Como símbolo esotérico se le adjudica un poder de atracción capaz de llegar a los dominios más difíciles y gran capacidad de protección.

4 Se destaca su presencia en la mayor parte de los planos relevados, en general realizados por constructores, aunque también por arquitectos y/o ingenieros destacados, como Alula Baldassarini, Alberto Córsico Piccolini o Auro Tiribelli, entre otros.

5 La palabra “devoción” tiene raíz en el latín devotione, y significa afecto, dedicación, sacrificio y culto. En la teología y en la espiritualidad católica, la devoción es un acto de religión. 
a las imágenes se dirigen a las personas representadas". Las imágenes escogidas implican que las personas que tienen como referencia a un santo para la devoción, admiran en él/ella sus normas, virtudes o ejemplo de vida, por lo que la contemplación de su carácter con afecto piadoso persigue un efecto que estimula su voluntad, a fin de hacerla recta y asemejarse. ${ }^{6}$ La veneración depositada en las imágenes encuentra su raíz en una "auténtica sed de Dios y 'un sentido perspicaz de sus atributos profundos: su paternidad, providencia, presencia amorosa y constante', su misericordia" (DPPL, 2002, n.61).

A esta función devocional se agrega la protectora, de forma tal que se recurre al motivo religioso como guardián de los habitantes de la casa. La protección es un cuidado preventivo ante un eventual riesgo o problema, e intenta impedir que una persona o una cosa sean dañadas. La protección puede ser física (concreta) o simbólica (abstracta). Así, en la protección abstracta representada en las fachadas, las imágenes se colocan con la misión de detener la posibilidad de sufrir perjuicios o alejar presencias oscuras y malignas. Esta forma de protección hogareña se reconoce desde tiempos antiguos, como acontecía, a modo de ejemplo, en el Imperio Romano a través de los altarcillos familiares formados con los dioses lares o mediante las inscripciones en las entradas de las casas con la leyenda cave canem ("cuidado con el perro"). Asimismo, las arquitecturas vernáculas en zonas de culto cristiano muestran abundantes ejemplos de protección de las casas, como los detentes con la representación del Sagrado Corazón dispuestos próximos a la puerta, para cerrarla simbólicamente a todo lo que pudiera colarse por ésta (Cruz Sánchez, 2009). También es posible reconocer detentes de María, cruces bendecidas ${ }^{7} \mathrm{o}$ inscripciones como 'Ave María' o 'IHS' (Jesús, Salvador de los hombres). ${ }^{8}$

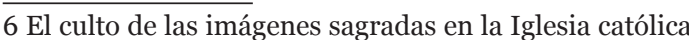
no es idolatría, la honra prestada a una imagen remonta al modelo original y quien venera una imagen, venera en ella a la persona representada. La honra prestada a las imágenes es una "veneración respetuosa", y no una adoración, que es debida solamente a Dios.

7 La cruz además de principal símbolo cristiano es también un símbolo esotérico que representa la vida eterna, la resurrección y la protección divina. Para los celtas fue sinónimo de culto y protección, de cuidado del descanso de los muertos, la protección de los hogares y los lugares de trabajo. Como todos los símbolos celtas sufrió la cristianización y también se la utilizó como símbolo político en algunas ocasiones.

8 Este monograma fue adoptado a partir de los años 1400 por grandes santos católicos, como San Vicente Ferrer y San Bernardino de Siena. Más tarde, San Ignacio de Loyola lo tomó para su sello como general de los jesuitas, quienes lo convirtieron en símbolo de la Orden.

\section{La cruz además de \\ principal símbolo cristiano \\ ES TAMBIÉN UN SÍMBOLO ESOTÉRICO QUE REPRESENTA LA VIDA ETERNA,}

\author{
LA RESURRECCIÓNY \\ LA PROTECCIÓN DIVINA.
}

De similar manera, en el caso de los chalets "estilo Mar del Plata" analizados, las advocaciones más recurrentes halladas en las fachadas evidencian deseos de protección asociada a manifestaciones devotas, en estrecha relación con la idiosincrasia religiosa local. Así es como acentúan las figuras de Cristo en la imagen del Sagrado Corazón de Jesús y la de Santa María Virgen a través de las advocaciones como la de Nuestra Señora de Luján, Nuestra Señora de Lourdes y Stella Maris, mediante materializaciones en mosaico o azulejo pintado, relieves o estatuillas de yeso.

Si bien, la devoción al Sagrado Corazón se remonta a finales del siglo XVII, no es sino hasta 1873 que fue formalmente aprobada por el Papa Pío Ix y hasta 1899 que el Papa León XIII recomendó a todos los obispos que la observaran en sus diócesis. Esto hace comprensible -en la cercanía temporal-, la proliferación de imágenes referidas a esta advocación. Podría decirse que, al momento de la construcción de las residencias analizadas, el Sagrado Corazón constituía una devoción alentada por la Iglesia de modo universal desde hace tan sólo algunas décadas.

Con las imágenes de María, en cambio, se nota la fortaleza de la localía. Las advocaciones elegidas reflejan la fe nacional, regional y local. Abarcan desde la patrona nacional, la Virgen de Luján (también patrona de las rutas y los ferrocarriles argentinos, y de la Policía Federal), hasta la Virgen de Lourdes, a quien se encomienda la salud de los enfermos y en cuyo honor se tiene en la ciudad un importante sitio para la vivencia de la piedad popular; la gruta de Lourdes emplazada en el barrio Puerto. 


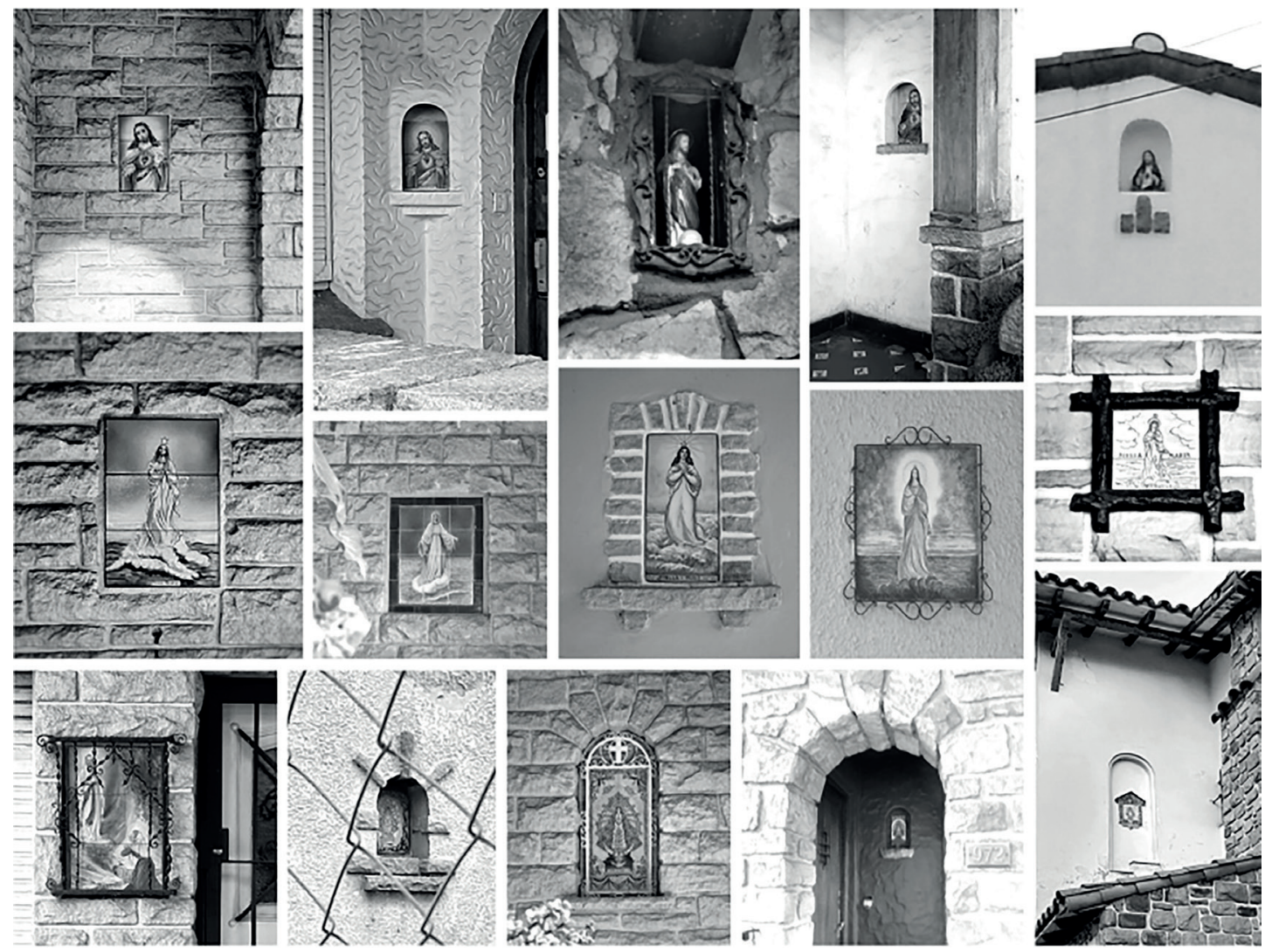

FIGURA 2. MOSAICO DE IMÁGENES DE LAS DEVOCIONES MÁS POPULARES EN LAS FACHADAS DE LOS CHALETS ANALIZADOS. FLLA SUPERIOR SAGRADO CORAZÓN DE JESÚS; FILA CENTRAL STELLA MARIS; FLLA INFERIOR (1] NUESTRA SENEORA DE LOURDES, [2 A 5] NUESTRA SEÑORA DE LUJÁN.

FUENTE: FOTOGRAFIAS DE LAS AUTORAS

Esta advocación de origen francés era de gran difusión en Europa en tiempos de la inmigración europea en nuestro país. Para esos años se trató de una advocación reciente en la Iglesia católica, dado que las apariciones de Lourdes tuvieron lugar en 1858 . Por otra parte, Mar del Plata contó con una presencia francesa que dejó relevantes huellas, como la empresa parisina "Société Nationale des Travaux Publics", que con sus ingenieros llevaron adelante las obras del puerto local entre 1913 y 1922. En paralelo y con gran presencia en la ciudad se encuentra la imagen de Stella Maris, la "estrella del mar", adoptada por la Armada Argentina como su patrona y la de los navegantes. En esta ciudad costera, donde el trabajo cotidiano en el mar fue -y es- una actividad característica, resulta frecuente observar embarcaciones, viviendas e instituciones dedicadas a ella y encomendadas a su protección.

Además de las mencionadas, otras imágenes suelen ser vistas con frecuencia, singularmente enlazadas a la inmigración italiana y española de principios del siglo xx: San Cayetano -santo italiano del siglo XVII, patrono del pan y del trabajo- y San José modelo de virtudes- en representaciones en las que se le aprecia con su típica vara florida, solo o con el niño Jesús.
En menor grado pueden mencionarse Nuestra Señora del Perpetuo Socorro, Santa Teresita del Niño Jesús, Santa Rosa de Lima - primera santa latinoamericanaNuestra Señora del Huerto, Nuestra Señora de Guadalupe -patrona de América Latina y de México- y Nuestra Señora de las Nieves -devoción de origen romano- entre otras imágenes.

En paralelo a esta profusión de imágenes todavía vigentes, en la actualidad casi la mitad de los vanos se encuentran vacíos o con funciones prácticas diversas (por ejemplo, con la colocación de sirenas de alarmas domiciliarias o bien, de cartelerías asociadas). El significado perdido $-\mathrm{O}$ encontradoconstituye una de las múltiples transiciones sociomateriales que evidencian cambios y transformaciones en proceso. El vaciamiento de la iconografía religiosa conlleva a meditar sobre la existencia, pérdida y mutación en la forma de sentirse protegido, creer, evocar y transmitir, especialmente en el ámbito doméstico público. Así, con la ausencia de la imagen, el elemento material pierde su naturaleza simbólica y convierte su rol a un ornamento meramente estético, o bien, a otro tipo de expresión intangible a ser develada. 


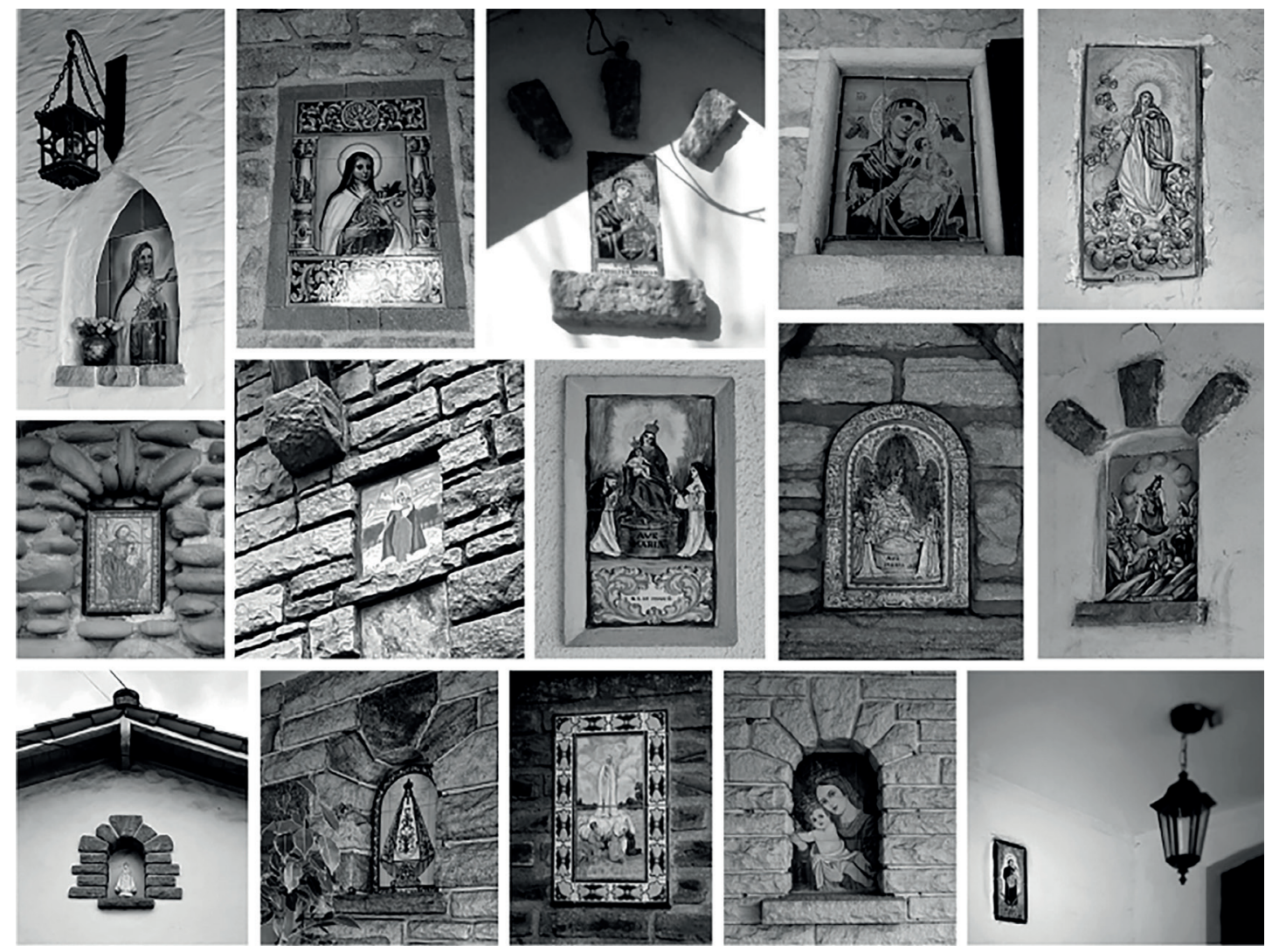

FIGURA 3. MOSAICO DE IMÁGENES DE LAS RESTANTES DEVOCIONES RELEVADAS EN LAS FACHADAS DE LOS CHALETS ANALIZADOS. FLA SUPERIOR [1Y 2] SANTA TERESTTA DEL NNNOO JESÚS, (3 Y 4) NUESTRA SENNORA DEL PERPETUO SOCORRO, (5) INMACULADA CONCEPCIÓN; FLLA CENTRAL (1) SAN JOSE,, (2) VIRGEN DE LAS NEVES, (3 Y 4) NUESTRA SEÑNORA DE POMPEYA, (5) NUESTRA SEÑ̃RA DEL CARMEN; FLLA INFERIOR (1 Y 2) NUESTRA SEÑORA DEL VALLE, (3) NUESTRA SEÑORA DE FÁTIMA, (4) NUESTRA SEÑORA DEL HUERTO, (5) SAN CAYETANO. FUENTE: FOTOGRAFIAS DE LAS AUTORAS.

\section{CONCLUSIONES}

Comunicar, manifestar, evidenciar una devoción y una necesidad de protección, son cualidades que tímidamente atesoran las imágenes de las fachadas de los chalets "estilo Mar del Plata", desde principios y mediados del siglo xx. Estos frentes que supieron condensar aspectos múltiples, con valores sociomateriales coligados con el devenir marplatense, se manifestaron -y manifiestan- mediante detalles a veces imperceptibles a miradas desatentas.

La dimensión religiosa se despliega en estas viviendas a través de imágenes inscriptas en el culto católico, con una selección que refleja la admisión e impulso de determinadas advocaciones, junto con apropiaciones particulares de acuerdo al forjamiento de la ciudad desde sus comienzos, entre la inmigración y el despliegue marítimo productivo e incluso ocioso. Así, la referencia a Cristo a través de la imagen del Sagrado Corazón evidencia los cruces con procesos mayores alentados por la Iglesia, mientras que entre las distintas advocaciones de la Virgen María se destaca, dentro de las condiciones territoriales y culturales locales, la de Stella Maris y su rol como protectora de los navegantes.

En paralelo, el vaciamiento de estos huecos murarios y la exhibición de los mismos -sin su eliminación u ocultacióntambién comunican y manifiestan otro tipo de procesos. Más todavía al ser ocupados por cartelerías o artefactos de seguridad, como las sirenas de alarmas, que aprovechan el vano como amparo para estas tecnologías y, en paralelo, inducen a pensar en otras formas de continuidades o rupturas en la necesidad y simbología de protección.

De esta forma, los valores de los chalets que en gran parte califican el paisaje de la ciudad, requieren, en paralelo a sus cuantías principalmente contextuales-ambientales, un mayor acercamiento a los detalles de apropiación popular que conservan, como las hornacinas evaluadas. Detalles que encierran formas de concebir la domesticidad en un sentido colectivo, entre múltiples actores involucrados -propietarios, constructores, 

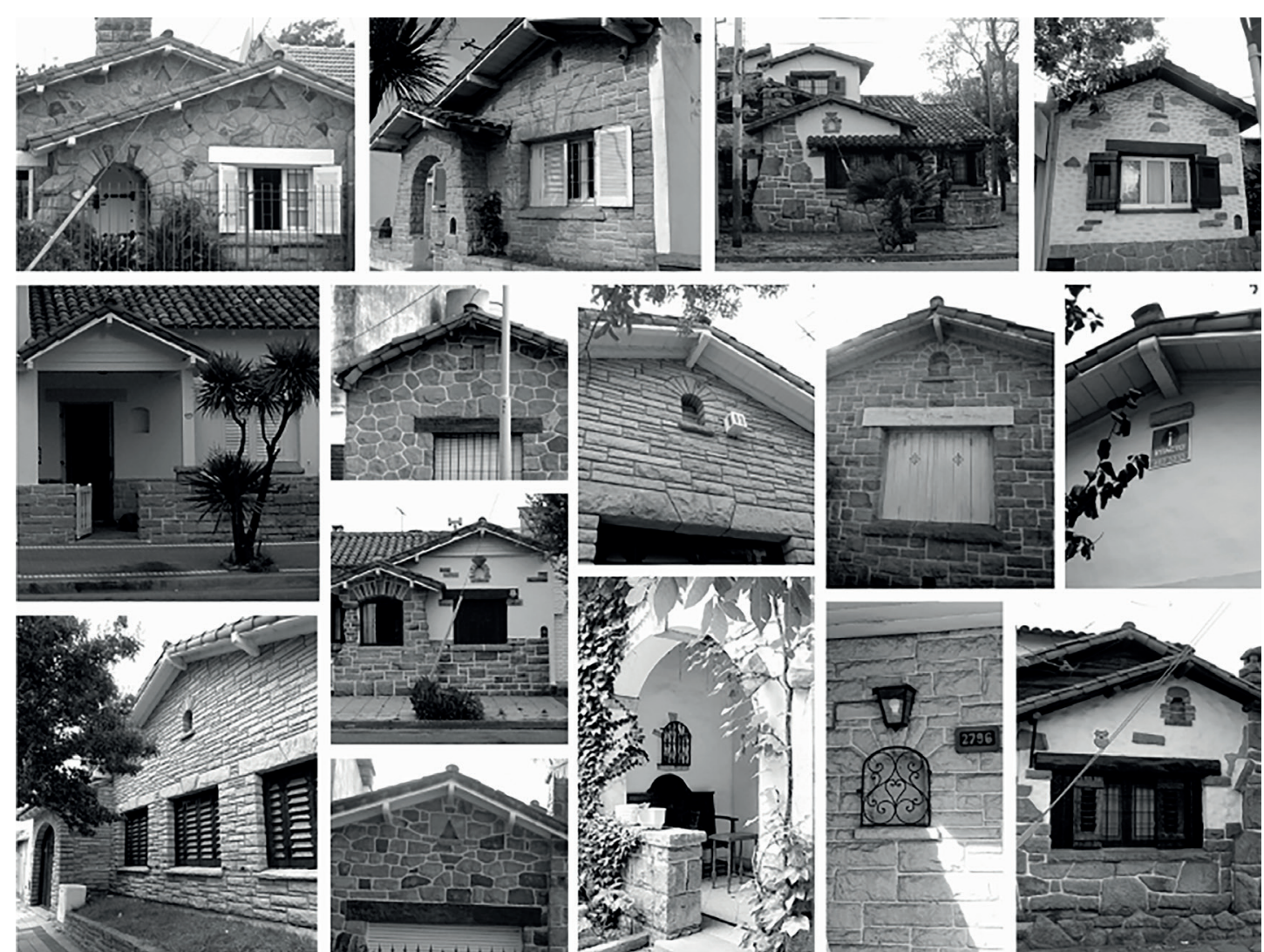

FIGURA 4. MOSAICO DE IMÁGENES DE HORNACINAS VACIAS EN LAS FACHADAS DE LOS CHALETS ANALIZADOS.

FUENTE: FOTOGRAFİAS DE LAS AUTORAS

arquitectos- y múltiples sentidos simbólicos latentes -religiosos, costumbristas, filiatorios- afincados en el devenir del territorio y su cultura.

Así, las aproximaciones analizadas esperan promover miradas más atentas hacia las referencias construidas entre el tiempo pasado y el presente, en tanto valores a interpretar e incluir dentro de las acciones de salvaguarda, junto con la inauguración de reflexiones, entre lo tangible y lo intangible, a dilucidarse mediante renovadas perspectivas temáticas.

\section{AGRADECIMIENTOS}

Agradecemos a la Arq. María Eugenia Millares y a la Guía de Turismo Victoria Gazzanego por su colaboración y aportación en la selección de las imágenes. 


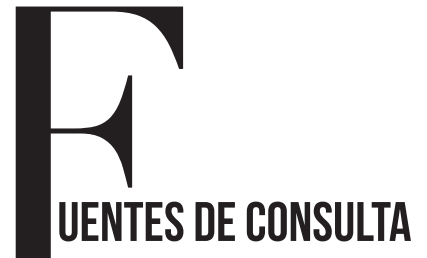

Argan, G. (1977), El concepto de espacio arquitectónico desde el Barroco a nuestros días, Nueva Visión, Buenos Aires.

Ballent, A. (2004), "Chalé (Chalet) y Pintoresca, Arquitectura" (términos). En Liernur, J. F. y Aliata, F. (comp.), Diccionario de Arquitectura en la Argentina, AGEA, Buenos Aires.

Benítez, A. (2017), "Las simbologías protectoras en las fachadas eclécticas”. En Novacovsky, A. y París Benito, F. et al. Textos de cátedra V. Mar del Plata: Universidad Nacional de Mar del Plata.

Cacopardo, F. (2003), La modernidad en una ciudad mutante. Vivienda, sociedad y territorio en la primera mitad del siglo $\mathrm{xx}$, FAUD-UNMDP, Mar de Plata.

Catecismo de la Iglesia Católica (1992), Disponible en http:// www.vatican.va/archive/catechism_sp/index_sp.html, consultado el 25 de junio de 2020.

Congregación para el Culto Divino y la Disciplina de los Sacramentos, Directorio sobre Piedad Popular y Liturgia (DPPL) (2002), Disponible en http://www.vatican.va/roman curia/congregations/ccdds/documents/rc con ccdds doc_20020513_vers-direttorio_sp.html, consultado el 02 de junio de 2020 .

Cova, R. y Gómez Crespo, R. (1982), Arquitectura marplatense. El pintoresquismo. Resistencia: Instituto Argentino de Investigaciones de Historia de la Arquitectura y del Urbanismo.

Cruz Sánchez, P. J. (2009), "La protección de las casas y sus moradores en El Rebollar (I). Algunos apuntes etnográficos en Robleda”, Revista Estudios del Patrimonio Cultural, 2, pp. 5-26. Disponible en https://sercam.es/estudios-del-patrimoniocultural/epc-02/, consultado el 15 de junio de 2020.

Francisco, P.P. (2013), Exhortación Apostólica Evangelii Gaudium, N. 133. Disponible en http://www.vatican.va/ content/francesco/es/apost_exhortations/documents/papafrancesco_esortazione-ap_20131124_evangelii-gaudium.html, consultado el 02 de junio de 2020.
Gendelman, I. y Aiello, G. (2010), "Faces of Places: Façades as Global Communication in Post-Eastern Bloc Urban Renewal". En Jaworski, A. y Thurlow, C. (eds.), Semiotic Landscapes: Language, Image, Space, Continuum, Londres.

Gómez Pintus, A. (2009), "Suburbio jardín y pintoresquismo. Una mirada historiográfica”, Bitácora Urbano Territorial, 1 (14), pp. 13-26. Disponible en https://revistas.unal.edu.co/index. $\mathrm{php} /$ bitacora/article/view/18505, consultado el 10 de junio de 2020 .

Hojman, M. y Rimbaud, T. (2018), "La fachada y el ornamento. Análisis histórico de las artes aplicadas en los frentes de la arquitectura patrimonial de Montevideo", VIII Encuentro de Docentes e Investigadores en Historia del Diseño, la Arquitectura y la Ciudad. Córdoba, mayo 2018, pp. 1492-1504. Disponible en http://www.fadu.edu.uy/investigacion/proyectosinvestigacion/tecnica-y-arte-en-la-ornamentacion-de-fachadasde-la-arquitectura-nacional-pautas-para-su-valoracion-yconservacion-patrimonial/, consultado el 10 de junio de 2020.

Loos, A. (1972), Ornamento y delito y otros escritos, GustavoGili, Barcelona.

París Benito, F. y Novacovsky A. (eds.) (2009), Alula Baldassarini. El impulsor de la arquitectura pintoresquista, FAUD-UNMDP, Mar del Plata.

Pérez Ortega, M. y García Serrano, R. (1969), "Hornacinas callejeras de Jaén”, Boletín del Instituto de Estudios Giennenses, 62, pp. 9-41.

Sánchez, L. M. (2008), "Mar del Plata y su patrimonio modesto: desde el pintoresquismo culto al popular. Génesis de los chalets “estilo Mar del Plata”, Revista $I+A, 11$, pp. 9-31.

Venturi, R., Izenour, S. y Scott Brown, D. (1978), Aprendiendo de Las Vegas. El simbolismo olvidado de la forma arquitectónica, Gustavo Gili, Barcelona. 